\title{
RANCANGAN VIDEO MEDIA PROMOSI BERBASIS MOTION GRAPHIC 2D UNTUK MENINGKATKAN JUMLAH MAHASISWA UNIVERSITAS WIDYAGAMA MALANG
}

\author{
Ria Diajeng Anita ${ }^{1}$, Fitri Marisa ${ }^{2}$ \\ diajeng17mn@gmail.com, fitrimarisa@widyagama.ac.id \\ Universitas Widyagama Malang
}

\begin{abstract}
In an agency needed a marketing process in order to sustain the system on that institution. Therefore, its necessary to create a media campaign that is attractive and effective. The authors designed a media campaign with the concept 2 dimensional animation, for university of Widyagama. Thats because an information will be more easily absorbed by presenting information through audio and the visuals. Animation designed by the author is in the form of $2 \mathrm{D}$ animation videos that explain and introduce University of Widyagama. 2D animation was created using Macromedia Flash 8 and edited with Adobe Premiere.
\end{abstract}

Intisari - Dalam suatu instansi diperlukan sebuah proses pemasaran untuk mempertahankan keberlangsungan sistem pada suatu instansi tersebut. Oleh karena itu, perlu diciptakan sebuah media promosi yang menarik dan efektif. Penulis merancang media promosi universitas widyagama malang dengan konsep animasi 2 dimensi. Hal ini dikarenakan sebuah informasi akan lebih mudah diserap dengan penyajian informasi melalui audio dan melalui visual. Animasi yang dirancang oleh penulis merupakan video animasi dalam bentuk 2D yang menjelaskan dan memperkenalkan universitas widyagama malang. Animasi 2D ini dibuat dengan menggunakan macromedia flash 8. Diedit dengan adobe premiere.

Kata kunci - Promosi, Animasi, Universitas Widyagama Malang

\section{PENDAhuluan}

Kebutuhan akan media promosi pada suatu instansi menjadi salah satu kebutuhan utama. Hal ini dikarenakan media promosi, merupakan media yang mempengaruhi keberlangsungan sistem pada suatu instansi. Media promosi seringkali digunakan pada industri perdagangan. Pada industri perdagangan tentunya promosi dilakukan untuk meningkatkan hasil penjualan produk. Namun pada instansi pendidikan, promosi diperlukan untuk menarik minat peserta didik untuk menempuh pendidikan di tempatnya. Universitas Widyagama merupakan salah satu kampus terkemuka di kota Malang yang sering disebut sebagai kampus inovasi. Perguruan Tinggi Swasta (PTS) ini keberadaannya menurut penulis dinilai masih kurang populer daripada Perguruan Tinggi Negeri (PTN) lainnya. Hal inilah yang melatarbelakangi penulis untuk mengembangkan media promosi yang menarik, untuk membantu meningkatkan minat peserta didik dan

\footnotetext{
${ }^{1}$ Mahasiswa, Universitas Widyagama Malang, Jl Patimura 6 no. 149 Batu 65315, (tlp: 0341-468921 e-mail: diajeng17mn@gmail.com)

2, Dosen Pengajar,Jurusan Teknik Informatika Universitas Widyagama Malang, Jln. Borobudur 35 Malang (telp: 0341468921; e-mail: fitrimarisa@widyagama.ac.id)
}

media. Kemampuan untuk memperoleh banyaknya mahasiswa tergantung dari penyampaian informasi Perguruan Tinggi Swasta (PTS) yang bersangkutan, melalui strategi pemasaran jasa yang diterapkan oleh Perguruan Tinggi Swasta (Siregar 2007). Oleh karena itu, untuk meningkatkan efektifitas kinerja media promosi, perlu dibuat semenarik mungkin agar dapat mencuri perhatian. Media audiovisual memiliki dua elemen yang masing-masing mempunyai kekuatan yang akan bersinergi menjadi kekuatan yang besar. Media ini memberikan stimulus pada pendengaran dan penglihatan, sehingga hasil yang diperoleh lebih maksimal. Hasil tersebut dapat tercapai karena pancaindera yang paling banyak menyalurkan informasi ke otak adalah mata (kurang lebih $75 \%$ sampai $87 \%$ ) sedangkan $13 \%$ sampai $25 \%$ pengetahuan diperoleh atau disalurkan melalui indera yang lain (dalam Lingga 2015). Gaya hidup anak remaja sekarang tidak jauh dari yang mananya teknologi, sehingga memungkinkan untuk dibuatkannya media promosi yang berunsurkan teknologi (Ulfa 2013). Seiring dengan perkembangan jaman dan semakin canggihnya teknologi, media promosi audio visual adalah animasi. Media animasi berdasarkan durasinya dibagi atas dua yaitu Short Form Animation (SFA) dan Long Form Animaton (LFA). Short Form Animation (SFA) adalah animasi berdurasi pendek, mulai dari 1 menit, 30 detik, atau 15 detik. Sementara Long Form Animaton (LFA) adalah animasi berdurasi panjang dan karya animasi yang dihasilkan biasanya berdurasi diatas 5 menit. $L F A$ lebih sering dikenal sebagai istilah Feature Film Animation atau animasi bioskop atau juga animasi untuk layar lebar. Biasanya durasinya minimal sekitar 70 menit (Ulfa 2013). Media animasi dirancang agar dapat menjadi media promosi yang mampu memberikan informasi yang menarik kepada masyarakat umum selain brosur (Ulfa 2013). Penulis memilih media animasi 2D jenis SFA (Short Form Animation) untuk merancang media promosi Universitas Widyagama Malang. Dengan SFA diharapkan, dapat menyajikan informasi yang akurat, tepat, dan efektif. Karena jika informasi disajikan terlalu lama, dapat mengurangi minat target promosi. Dengan memanfaatkan kemampuan visual, akan dirancang animasi dengan gambar yang menarik. Agar informasi yang diserap lebih optimal.

\section{KAJIAN PUSTAKA}

\section{A. Media Promosi}

Promotion berasal dari bahasa latin Promovere, pro berarti Forward (ke depan) dan movere berarti move (bergerak). Jadi dapat dikemukakan bahwa promosi "to move forward" atau bergerak ke arah depan (Siregar 2007). Dalam perdagangan, promosi adalah suatu kegiatan untuk menarik minat konsumen terhadap produk yang dijual. Dalam tujuan 
promosi pada hubungannya dengan teori ekonomi adalah untuk merubah letak dan kondisi kurva permintaan suatu produk pada suatu perusahaan (Siregar 2007). Sehingga promosi selalu identik dengan peningkatan penjualan. Seiring dengan berkembangnya kemajuan teknologi, media promosi tidak hanya melalui media cetak, dan elektronik saja. Akan tetapi media internet juga merupakan media yang paling populer saat ini. Semakin banyaknya kompetitor, pasti akan mempengaruhi kualitas media promosi suatu instansi. Media promosi merupakan alat yang digunakan untuk menyampaikan informasi. Oleh karena itu media promosi dituntut untuk selalu menarik. Semakin menarik media promosi yang digunakan, maka akan semakin banyak hasil penjualan yang didapatkan. Begitu pula sebaliknya. Media cetak seperti koran, tabloid, majalah, katalog, brosur dan poster perlahan sudah mulai ditinggalkan oleh masyarakat. Hal ini dikarenakan terdapat media promosi dengan memanfaatkan internet yang lebih mudah digunakan. Beberapa alat promosi, atau yang lebih dikenal dengan bauran promosi (promotion mix) terdiri atas empat variabel (Anggayani 2014) yaitu :

a. Periklanan

Periklanan merupakan media promosi yang berbayar. Para pemasar menggunakan iklan untuk memenuhi tiga tujuan utama yaitu untuk menginformasikan, membujuk, dan mengingatkan kembali (Anggayani 2014).

b. Penjualan Individu (Personal Selling)

Yang dimaksud dalam penjualan individu adalah, bertemunya 2 individu dalam suatu interaksi untuk saling menguntungkan.

c. Publicity

Kegiatan promosi dengan cara menyebarkan berita yang tidak berbayar.

d. Promosi Penjualan

Kegiatan promosi untuk menarik minat konsumen. Contohnya memberikan hadiah, doorprize atau bonus dan lain - lain untuk setiap pembelian yang dilakukan oleh konsumen.

\section{B. Animasi}

Animasi berarti menghidupkan urutan still image atau gambar tidak hidup atau teknik menfilmkan susunan gambar atau model untuk menciptakan rangkaian gerakan ilusi. Jadi, animasi itu dibentuk dari model-model yang dibuat secara grafis yang kemudian digerakkan (dalam Ulfa 2013). Media animasi berdasarkan durasinya dibagi atas dua yaitu Short Form Animation (SFA) dan Long Form Animaton (LFA). Short Form Animation (SFA) adalah animasi berdurasi pendek, mulai dari 1 menit, 30 detik, atau 15 detik. Sementara Long Form Animaton (LFA) adalah animasi berdurasi panjang dan karya animasi yang dihasilkan biasanya berdurasi diatas 5 menit. LFA lebih sering dikenal sebagai istilah Feature Film
Animation atau animasi bioskop atau juga animasi untuk layar lebar. Biasanya durasinya minimal sekitar 70 menit (dalam Ulfa 2013). Animasi adalah memberi arti "menghidupkan" suatu benda atau obyek yang seolah-olah bergerak hidup sehingga dapat dinikmati dan dirasakan, adegan dalam menggerakkan wayang dalam seni wayang kulit merupakan cikal bakal animasi sehingga animasi modern merupakan salah satu unsur penunjang yang sangat penting dalam memproduksi sebuah aplikasi multimedia. Prinsip dasar animasi adalah menjalankan gambar-gambar yang terlihat frame per frame secara berangkaian dan hampir bersamaan, sehingga terlihat seolah gambar tersebut bergerak (Iskandar, Novantara \& Sugiharto 2014).

\section{MOTION GRAPHIC}

Motion graphic adalah potongan-potongan media visual berbasis waktu yang menggabungkan film dan desain grafis. Hal tersebut bisa dicapai dengan menggabungkan berbagai elemen-elemen seperti animasi 2D dan 3D, video, film, tipografi, ilustrasi, fotografi, dan music (Sukarno 2014). Pengertian lain tentang motion graphic adalah grafis yang menggunakan video dan atau animasi untuk menciptakan ilusi dari gerak ataupun transformasi. Graphic design telah berubah dari static publishing dengan memanfaatkan teknologi komunikasi termasuk film, animasi, media interaktif, dan environmental design (dalam Humairah, 2015).

\section{Media Pembelajaran}

Banyak taksonomi dengan berbagai pendekatan dibuat oleh para ahli media, diantaranya Edling [12] yang dalam usahanya beranggapan bahwa siswa, rangsangan belajar dan tanggapan merupakan variabel kegiatan belajar dengan media. Menurut Edling media merupakan bagian dari enam unsur rangsangan belajar, yaitu dua untuk pengalaman audio meliputi kodifikasi subjektif visual dan kodifiikasi subjektif audio, dua untuk pengalaman visual melalui kodifikasi subjek audio dan kodifikasi objektif visual, dan dua

pengalaman belajar 2 dimensi meliputi pengalaman langsung dengan orang dan pengalaman langsung dengan benda-benda. Media pembelajaran merupakan salah satu komponen pembelajaran yang mempunyai peranan penting dalam kegiatan belajar mengajar. Pemanfaatan media seharusnya merupakan bagian yang harus mendapat perhatian guru/fasilitator dalam setiap kegiatan pembelajaran. Oleh karena itu guru/fasilitator perlu mempelajari bagaimana menetapkan media pembelajaran agar dapat mengefektifkan pencapaian tujuan pembelajaran dalam proses belajar mengajar. Menurut Mustikasari [13] istilah media berasal dari bahasa latin yang merupakan bentuk jamak dari medium. Secara harfiah berarti perantara atau

pengantar. Pengertian umumnya adalah segala sesuatu yang dapat menyalurkan informasi dari sumber informasi kepada penerima informasi. Media menurut AECT atau Association for Educational Communications and Technology [13] adalah segala sesuatu yang digunakan orang untuk menyalurkan pesan. Sedangkan Gagne [13] mengartikan media sebagai 
jenis komponen dalam lingkungan siswa yang dapat merangsang mereka untuk belajar. Briggs [13] mengartikan media sebagai alat untuk memberikan perangsang bagi siswa agar terjadi proses belajar.

\section{ANALISA PERANCANGAN}

\section{A. Perancangan}

Sebuah karya film kartun tidak akan terlihat bagus jika cerita yang disuguhkan dalam film tersebut juga tidak menarik. Untuk membuat cerita yang bagus sangat diperlukan struktur cerita yang jelas (Iskandar, Novantara \& Sugiharto 2014). Terdapat beberapa tahap dalam membuat animasi motion graphic. Tahapan tersebut terbagi menjadi 3 yaitu, pra produksi, produksi, dan pasca produksi. Tahap pra produksi merupakan tahapan awal sebelum pembuatan animasi motion graphic. Tahap ini meliputi : pembuatan ide konsep, pembuatan naskah cerita, pembuatan rancangan alur cerita, perancangan animasi, mempersiapkan Sumber Daya Manusia (SDM) yang dibutuhkan, perancangan kostum, perancangan setting lokasi, serta penjadwalan pembuatan animasi.

\section{B. Tahap Produksi}

Dari penjelasan sebelumnya maka hal pertama yang perlu dilakukan adalah menyusun skenario. Dalam film nyata pengambilan gambar dapat diambil dengan mudah oleh kameraman dengan menggunakan kamera video. Sutradara dapat mengambil posisi dan sudut pandang tiap adegan tanpa kesulitan berarti. Sedangkan dalam film kartun, pengambilan gambar direncanakan dengan menggunakan imajinasi terlebih dahulu, membayangkan sudut pandang yang pas dan enak dilihat (Iskandar, Novantara \& Sugiharto 2014).

Berikut ini adalah skenario yang akan disusun menjadi sebuah video motion graphic $2 \mathrm{D}$ :

1. Anak sma/smk berada di sekolahnya dan menerima surat kelulusan, dan dinyatakan lulus.

2. Kemudian, anak tersebut pulang dengan mengendarai sepeda motornya.

3. Dengan riang gembira anak tersebut sambil bersiul - siul ditengah jalan dan menoleh ke kanan dan ke kiri.

4. Tiba - tiba dia melihat sebuah kampus di pinggir jalan yang mencuri perhatiannya dengan tulisan "kampus inovasi".

5. Seketika, dia langsung masuk ke dalam kampus tersebut, untuk mencari informasi.

6. Universitas widyagama merupakan universitas satu - satunya di kota malang yang memiliki gelar kampus inovasi.

7. Kampus ini memiliki 2 kampus utama, yaitu kampus II dan kampus III. Kampus II bertempat di jalan Borobudur nomor 35 , sedangkan kampus III bertempat di jalan taman borobudur indah 3 malang.
8. Kampus widyagama malang membuka 3 program pendidikan. Pendidikan Diploma, Sarjana, dan Pasca Sarjana.

9. Pendidikan diploma memiliki 2 program keahlian yaitu, keuangan dan perbankan syariah dan otomotif.

10. Pendidikan sarjana memiliki 4 fakultas yaitu fakultas ekonomi, fakultas hukum, fakultas pertanian, dan fakultas teknik.

11. Fakultas ekonomi terdiri dari program studi akuntansi dan program studi manajemen.

12. Fakultas hukum terdiri dari program studi hukum perdata/bisnis, hukum pidana, dan hukum tata negara.

13. Fakultas pertanian terdiri dari program studi agribisnis, agroteknologi, dan teknologi hasil pertanian.

14. Fakultas teknik terdiri dari program studi teknik elektro(energi listrik/tenaga elektronik, telekomunikasi),teknik industri, teknik mesin, teknik sipil dan teknik informatika.

15. Pendidikan pasca sarjana memiliki 2 program yaitu, program magister manajemen (manajemen SDM,manajemen keuangan, manajemen pemasaran), dan program magister hukum (hukum kenegaraan dan ham, hukum pidana, hukum ekonomi/bisnis).

16. Untuk info lebih lanjut bisa menghubungi Telpon 0341-491648,0341-411291, 0341492282 atau fax 0341-491648, 496919. Atau klik website http://www.widyagama.ac.id

\section{Persiapan Kebutuhan Alat}

1. Laptop / PC dengan RAM 8 GB

2. Operating System Windows 7/ 8, 32-64 bit

3. Resolusi Layar $1280 \times 800$ (minimum)

4. Macromedia Flash 8 (untuk kebutuhan pembuatan animasi)

5. Adobe Premier (untuk kebutuhan editing suara)

6. Corel Draw X4 (untuk kebutuhan pembuatan gambar/karakter/background)

7. Adobe Audition (untuk kebutuhan render)

a. Rancangan Alur Cerita

\begin{tabular}{l|l|l|l|l} 
BABAK I & \multicolumn{2}{l}{ BABAK } & \multicolumn{2}{l}{ BABAK III } \\
\multicolumn{1}{l}{ II } & \multicolumn{2}{l}{ Promosi } \\
Persiapan & \multicolumn{2}{l}{ Tertarik } & \multicolumn{2}{c}{ Prom } \\
\hline
\end{tabular}




\begin{tabular}{|c|c|c|c|}
\hline \multirow[t]{2}{*}{$\begin{array}{l}\text { Siswa } \\
\text { siswi SMA } \\
\text { / SMK } \\
\text { lulus ujian }\end{array}$} & $\begin{array}{l}\text { Setting } \\
\text { keliling } \\
\text { kota } \\
\text { malang }\end{array}$ & $\begin{array}{l}\text { Memilih } \\
\text { fakultas } \\
\text { yang } \\
\text { diminati }\end{array}$ & $\begin{array}{l}\text { an } \\
\text { as } \\
\text { ma } \\
\text { mua }\end{array}$ \\
\hline & kerja & & \\
\hline
\end{tabular}

Gambar 3.4. Bagan Scene Motion graphic 2D

\section{HASIL DAN PEMBAHASAN}

\section{A. PEMBUATAN DESAIN OBJEK 2D}

Pembuatan desain objek 2D dilakukan pada corel draw X4. Berikut ini adalah hasil pembuatan karakter animasi 2D untuk motion graphic Universitas Widyagama Malang.

Semua karakter dieksport menjadi ekstensi SWF. Klik menu File $=>$ Export $=>S W F$. Hal ini bertujuan agar file gambar bisa dipisah - pisah di Macromedia Flash 8.

\section{B. MOTION GRAPHIC (PROSES PENGGERAKAN ANIMASI)}

Langkah selanjutnya adalah proses pembuatan gerakan pada karakter yang sudah dibuat sebelumnya. Tool yang digunakan adalah macromedia flash 8. Langkah - langkahnya berikut ini:

1. Buka software macromedia flash 8

2. Pilih file $=>$ new $=>$ flash document

3. Tentukan ukuran layar klik size

4. Atur dimensi menjadi lebar 1280 dan panjang 720 px

5. Klik file $=>$ import $=>$ import to library.

6. Pilih file berekstensi SWF yang sudah disimpan dari proses sebelumnya.

7. Maka akan terlihat tampilan berikut ini, seprti yang terlihat pada kotak merah kanan bawah.

8. Untuk memberikan gerakan pada scene tersebut, cukup drag scene yang ada pada kanan bawah menuju frame putih.

9. Atur scene sesuai dengan size pada layar kerja.
10. Kemudian pisah - pisah gambar scene sesuai dengan layernya.

11. Lakukan setting pergerakkan animasi pada tools timeline yang ada diatas layar kerja.

12. Pada timeline klik kanan $=>$ create motion tween $\Rightarrow$ insert keyframe

Pada langkah ini akan diatur di detik keberapa gerakan yang sesuai dengan karakter akan berjalan. Sebelumnya pastikan karakter yang bergerak sudah dipisah dari karakter yang tidak digerakkan.

\section{BACKSOUND}

Pemilihan backsound yang sesuai dengan animasi, sangat mempengaruhi menarik tidaknya animasi tersebut. Oleh karena itu, backsound harus juga disesuaikan dengan gambar yang sedang berjalan. Penambahan baksound dilakukan pada software adobe premier.

\section{RECORD NARASI}

Setelah menyisipkan backsound pada animasi yang telah kita buat, selanjutnya buatlah narasi yang juga sesuai dengan gambar. Untuk mendukung backsound dan visualisasinya. Perekaman narasi seharusnya dilakukan di tempat yang kondusi, agar proses perekaman dapat berjalan dengan lancar.

\section{E.EDITING DAN FINALISASI}

Berikut ini merupakan gambar screenshoot pembuatan pergerakan motion graphic 2D untuk media pormosi Universitas Widyagama Malang.

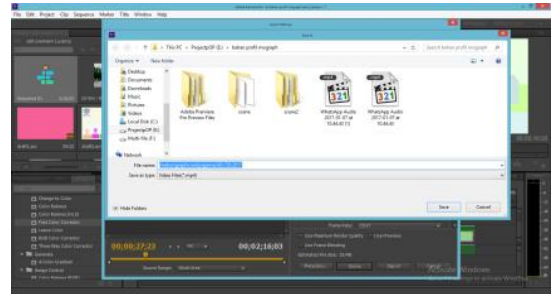

Gambar 1 Proses Edit 1

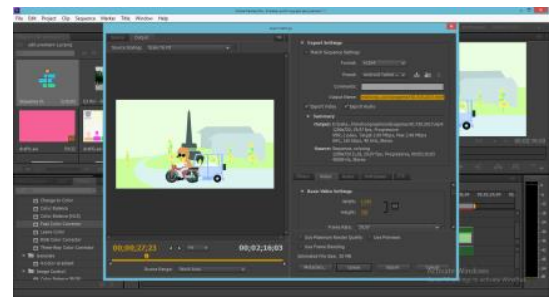

Gambar 2 Proses Edit 2 


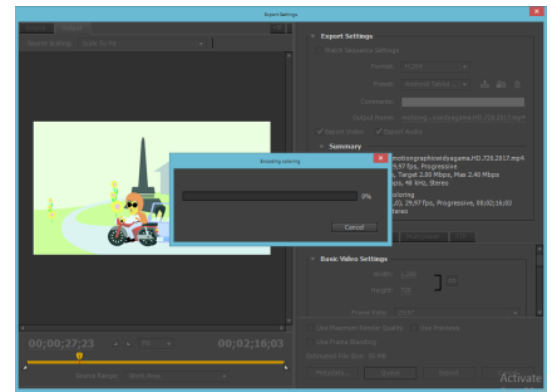

Gambar 3 Proses Edit 3

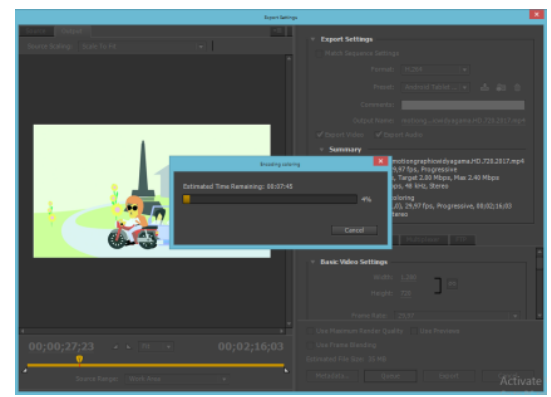

Gambar 4 Proses Edit 4

\section{UCAPAN TERIMA KASIH}

Terima kasih disampaikan kepada Dosen Pembimbing, dan staff pengajar SMK PGRI 3 Malang, serta teman - teman jurusan Teknik Informatika 2013, yang mendukung project ini.

\section{REFERENSI}

[1] Anggayani, CP 2014, 'Perancangan Media Promosi Wisata Taman Narmada', Jurnal DKV Adiwarna, Universitas Kristen Petra, vol 1, no. 4.

[2] Iskandar, Novantara, P \& Sugiharto, T 2014, 'RANCANG BANGUN ANIMASI FILM KARTUN SEJARAH DAN KEMAJUAN UNIVERSITAS KUNINGAN SEBAGAI MEDIA INFORMASI DAN PROMOSI BERBASIS ADOBE FLASH CS 3', Jurnal Penelitian Universitas Kuningan.

[3] Iskandar, Novantara, P \& Sugiharto, T 2014, 'RANCANG BANGUN ANIMASI FILM KARTUN SEJARAH DAN KEMAJUAN UNIVERSITAS KUNINGAN SEBAGAI MEDIA INFORMASI DAN PROMOSI BERBASIS ADOBE FLASH CS3', Jurnal Penelitian Universitas Kuningan, vol 5, no. 1, p. 12.

[4] Siregar, A 2007, 'PENGARUH BAURAN PROMOSI PEMASARAN TERHADAP KEPUTUSAN MAHASISWA MEMILIH SEKOLAH TINGGI ILMU EKONOMI (STIE) ITMI MEDAN', Pasca Sarjana, Universitas Sumatera Utara, USU e-Repository, Medan.

[5] Siregar, A 2007, 'PENGARUH BAURAN PROMOSI PEMASARAN TERHADAP KEPUTUSAN MAHASISWA MEMILIH SEKOLAH TINGGI ILMU EKONOMI(STIE) ITMI MEDAN', Pasca Sarjana Universitas Sumatera Utara, USU e -Repository, Medan.

[6] Sukarno, IS 2014, 'PERANCANGAN MOTION GRAPHIC ILUSTRATIF MENGENAI MAJAPAHIT UNTUK PEMUDAPEMUDI', Jurnal Tingkat Sarjana bidang Senirupa dan Desain, p. 1.

[7] Ulfa, A 2013, 'PERANCANGAN MEDIA PROMOSI PROGRAM STUDI DESAIN KOMUNIKASI VISUAL UNIVERSITAS NEGERI PADANG BERBASIS ANIMASI', Seni Rupa, Fakultas Bahasa dan Seni, Universitas Negeri PAdang, Padang. 